\title{
Contribuições da Pedagogia Progressista Libertadora para a Educação Inclusiva Frente ao Contexto Neoliberal
}

\author{
Fernando Soares Machado*- IFTM-MG \\ Elisa Antônia Ribeiro**-IFTM-MG \\ Geraldo Gonçalves de Lima*** IFTM-MG
}

\section{Resumo}

O discurso de inclusão educacional, voltado à igualdade de oportunidades e à educação para todos, camufla-se sob o domínio das teorias educacionais de base econômica instituídas nas políticas públicas brasileiras, com fins produtivistas, que exacerbam o individualismo e as desigualdades. As teorias progressistas confrontam-se a esse sistema propondo uma educação pautada na luta de classes e na transformação social. O presente estudo tem como objetivos compreender a concepção das políticas direcionadas à educação inclusiva no cenário brasileiro, a partir dos anos de 1990, por influência do neotecnicismo pedagógico, e apresentar possíveis contribuições da teoria progressista libertadora para a inclusão educacional. $\mathrm{O}$

* Discente do Programa de Pós-graduação - Mestrado Profissional em Educação Tecnológica - Profept, Instituto Federal do Triângulo Mineiro - IFTM - Campus Uberaba Parque Tecnológico. fernando80sm@gmail.com

** Docente do Programa de Mestrado Profissional do Programa de Pós-Graduação em Educação Profissional e Tecnológica -ProfEPT - Instituto Federal do Triângulo Mineiro (IFTM-MG). Pós-Doutorado em Educação pela Universidade Federal de Uberlândia (UFU). Doutora em Educação (UFU). elisa.ribeiro@iftm.edu.br

*** Docente do Programa de Mestrado Profissional do Programa de Pós-Graduação em Educação Profissional e Tecnológica -ProfEPT - Instituto Federal do Triângulo Mineiro (IFTM-MG). Pós-Doutorado em Educação pela Universidade Federal de Uberlândia (UFU). Doutor em Educação pela Universidade Federal de Uberlândia (UFU). Mestre em Educação pela Universidade Federal de Uberlândia . Licenciado e Bacharel em Filosofia pela Pontifícia Universidade Católica de Campinas - São Paulo (PUCCAMP - SP). geraldolima@iftm.edu.br 
método utilizado tomou como base uma pesquisa qualitativa, envolvendo a análise da legislação referente ao tema (documental) e bibliográfica, a partir de publicações de autores que discutem a inclusão como apropriação do neoliberalismo e das ideias defendidas por Paulo Freire. Assim, a pedagogia libertadora fundamenta-se como uma alternativa de ruptura da lógica neoliberal ao defender uma educação dialógica por meio de uma práxis que inclua, que se preocupa com a construção coletiva, crítica, política, consciente e reflexiva, pautada em uma educação enquanto ambiente de transformação dos sujeitos.

Palavras-chave: Inclusão. Neoliberalismo. Pedagogia libertadora.

\section{Contributions of The Liberating Progressive Pedagogy to inclusive Education In The Neoliberal Context}

\section{Abstract}

The discourse of educational inclusion, aimed at equal opportunities and education for all, is camouflaged under the domain of educational theories of economic base instituted in Brazilian public policies, with productivist purposes, which exacerbate individualism and inequalities. Progressive theories confront this system by proposing an education based on class struggle and social transformation. The present study aims to understand the conception of policies aimed at inclusive education in the Brazilian scenario, starting in the 1990 s, due to the influence of pedagogical neotechnics, and to present possible contributions from the liberating progressive theory to educational inclusion. The method used was based on a qualitative research, involving the analysis of legislation related to the (documentary) and bibliographic theme, based on publications by authors who discuss inclusion as the appropriation of neoliberalism and the ideas defended by Paulo Freire. Thus, the liberating pedagogy is founded as an alternative to rupture the neoliberal logic by defending a dialogical education through a praxis that includes, that is concerned with the collective, critical, political, conscious and reflective construction, based on an education and transformation environment of the subjects.

Keywords: Inclusion. Neoliberalism. Liberating pedagogy. 


\section{Contribuciones de la Pedagogía Progresiva Liberadora a la Educación Inclusiva en el Contexto Neoliberal}

\section{Resumen}

El discurso de inclusión educativa, dirigido a la igualdad de oportunidades y educación para todos, está camuflado bajo el dominio de las teorías educativas de base económica instituidas en las políticas públicas brasileñas, con fines productivistas, que exacerban el individualismo y las desigualdades. Las teorías progresivas confrontan este sistema al proponer una educación basada en la lucha de clases y la transformación social. El presente estudio tiene como objetivo comprender la concepción de políticas dirigidas a la educación inclusiva en el escenario brasileño, a partir de la década de 1990, debido a la influencia de la neotecnia pedagógica, y presentar posibles contribuciones de la teoría progresiva liberadora a la inclusión educativa. El método utilizado se basó en una investigación cualitativa, que involucró el análisis de la legislación relacionada con el tema (documental) y bibliográfico, basado en publicaciones de autores que discuten la inclusión como la apropiación del neoliberalismo y las ideas defendidas por Paulo Freire. Así, la pedagogía liberadora se fundamenta como una alternativa para romper la lógica neoliberal defendiendo una educación dialógica a través de una praxis que incluye, que se preocupa por la construcción colectiva, crítica, política, consciente y reflexiva, basada en la educación como Entorno de transformación de los sujetos.

Palabras clave: Inclusión. Neoliberalismo. Pedagogía liberadora

\section{Introdução}

$\mathrm{Na}$ Contemporaneidade ${ }^{1}$, a inclusão escolar é amplamente defendida pela sociedade como uma forma de garantia de direitos e igualdade de oportunidades a todos os sujeitos, independentemente do nível social, da cor, de raça, de gênero e de deficiência.

A contemporaneidade - também chamada de pós-modernidade, modernidade tardia ou modernidade reflexiva é uma etapa que se caracteriza por aceleração e intensificação do ritmo de vida, uso intenso de tecnologias de informação e comunicação. É uma época marcada por dinamismo e rapidez, mas, também, por instabilidade, imprevisibilidade, insegurança e fluidez. A flexibilidade e a constante renovação também são características do mundo contemporâneo, as quais se associam, diretamente, com a descartabilidade e o consumismo (BAUMAN, 2001). 
Com isso, "se o que pretendemos é que a escola seja inclusiva, é urgente que seus planos se redefinam para uma educação voltada para a cidadania global, plena, livre de preconceitos e que reconhece e valoriza as diferenças" (M ANTOAN, 2003, p. 20).

Assim, a inclusão educacional tem adquirido densidade nas discussões no final do século XX e início do XXI, principalmente a partir da intensificação de agências multilaterais lideradas pelo Banco Mundial, Fundo Monetário Internacional (FMI), Organização das Nações Unidas (ONU) e Organização das Nações Unidas para a Educação, a Ciência e a Cultura (UNESCO). Essas agências são responsáveis pela implementação de proposições relevantes em favor da universalização da educação básica, principalmente do ensino fundamental. Preconizam o princípio da educação para todos, incluindo as pessoas com deficiência, contemplados na Conferência de Educação para Todos (Declaração de Jomtien - 1990) e sobre as Necessidades Educacionais Especiais (Declaração de Salamanca 1994), das quais o Brasil é signatário.

Com advento dos anos 1980, caracterizados pela abertura política e pela governabilidade de cunho democrático, há uma grande influência desse movimento internacional, sobretudo no direcionamento de implementação de políticas públicas inclusivas no Brasil. A Constituição Federal de 1988 - CF/1988, concatenada a esse processo, estabelece como princípios fundamentais a soberania e a cidadania. Além disso, constitui como um de seus objetivos fundamentais, no Art. $3^{\circ}$, inciso quarto: "promover o bem de todos, sem preconceitos de origem, raça, sexo, cor, idade e quaisquer outras formas de discriminação" (BRASIL, 2020, p. 10).

O documento constituinte permitiu a possibilidade de modificação da sociedade brasileira ao se afirmarem os princípios de uma sociedade inclusiva. Logo, a educação passa a ser um direito extensivo a todos, sendo o Estado o primeiro responsável e, posteriormente, a família (SILVA; MARQUES, 2013).

Por conseguinte, a própria Lei de Diretrizes e Bases da Educação Nacional, no 9.394/96 (LDBEN/1996) ratifica a CF/1988 ao estabelecer como finalidades da Educação Nacional a formação para 
o exercício da cidadania e o preparo para o trabalho, contemplando como um dos princípios, no Art. 30 "I - igualdade de condições para acesso e permanência na escola [...]" (BRASIL, 1996, p. 9).

De fato, essas políticas orientam-se a partir de princípios inclusivos, entretanto há algumas controvérsias neste processo, visto que o alicerce de sustentação desses documentos está relacionado às teorias educacionais de base econômica que preconizam a educação como um elemento de desenvolvimento humano, com um enfoque multiculturalista (DI GIORGI, 1996 apud SILVA, 2014).

Nesse sentido, a inclusão pode ser definida como um imperativo sob a égide do Estado, pois "[...] torna-se uma das estratégias contemporâneas mais potentes para que o ideal da universalização dos direitos individuais seja visto como uma possibilidade [...]" (LOPES; FABRIS, 2016, p. 8). Há um modelo forjado de inclusão que ganha mais espaço na Contemporaneidade, principalmente pelo aumento das desigualdades entre os sujeitos e suas condições de vida (LOPES; FABRIS, 2016).

Desse modo, existe uma influência marcante do ideário neoliberal reproduzida pelo neotecnicismo educacional, uma vez que, neste cenário, o ensino volta-se às necessidades de mercado. Observa-se uma escola de preparação do novo trabalhador, potencialmente de base operacional, restringindo-se ao ensino de métodos e conteúdos específicos, consoante as demandas do capitalismo.

O neotecnicismo, enquanto forma de organização da escola, se faz presente por meio da introdução do método de gerenciamento produtivo-industrial denominado de "Qualidade Total" (SAVIANI, 2008 apud SILVA, 2014). Abordando este cenário controverso de uma educação gerencial, a inclusão passa a ser um instrumento de exacerbação ao individualismo, uma vez que são criados mecanismos de vinculação dos indivíduos no que tange à dependência financeira. Por conseguinte, a inclusão depende do esforço de cada um para manter-se nos vários ambientes da sociedade.

Nesse caso, é possível pensar em uma educação inclusiva de formação cidadã, de igualdade de direitos para todos, em um contexto neoliberal, de neotecnicismo pedagógico? 
Assim, se faz necessária uma contraposição a esse modelo neotecnicista, no qual a educação inclusiva está relacionada. Consequentemente, entende-se que uma das maneiras de confrontar e modificar a educação gerencial se traduz pelo aporte epistemológico da teoria progressista, mais precisamente, sob os pressupostos da pedagogia libertadora de Paulo Freire.

A tendência pedagógica progressista é condicionada pelos aspectos sociais, educacionais, políticos e culturais. Deste modo, existe a possibilidade de transformação social a partir da compreensão da realidade histórica. Enquanto sujeitos sociais, há o favorecimento da formação crítica e da ruptura de interesses de uma educação exclusivamente mercadológica e excludente, imposta pelos poderosos.

Coerente com essa perspectiva, o presente artigo tem como objetivos compreender a concepção das políticas direcionadas à educação inclusiva no cenário brasileiro, a partir dos anos de 1990, sob a influência do neotecnicismo pedagógico, e apresentar possíveis contribuições da teoria pedagógica progressista libertadora para a inclusão educacional.

Para a realização do presente estudo, optou-se pelo desenvolvimento de uma pesquisa qualitativa e de cunho documental e bibliográfico. A primeira etapa do estudo resultou da análise de documentos internacionais e nacionais, os quais servem de referenciais e norteadores para a implementação da educação inclusiva.

Posteriormente, realizou-se uma análise bibliográfica de produções científicas sobre a inclusão educacional, no contexto neoliberal, caracterizado pela pedagogia neotecnicista. Como proposta de contraposição, foram investigados os ideais progressistas presentes nas obras de Paulo Freire e suas possíveis contribuições para a compreensão e a consolidação de uma educação inclusiva, que transcenda o viés alienante discursivo rumo à construção de escola crítica, reflexiva e de oportunidades para todos. 


\section{A educação inclusiva e o contexto brasileiro do neotecnicismo pedagógico}

Com o advento dos anos de 1990, há um movimento político internacional fomentado por órgãos como a ONU, a UNES$\mathrm{CO}$ e o Banco Mundial, que convergia ações em defesa de uma sociedade inclusiva, tendo em vista a necessidade de se contrapor a um modelo histórico de desigualdades de ordem social, econômica, educacional e do trabalho.

A Declaração Mundial sobre Educação para Todos (1990), conhecida como "Declaração de Jomtien", foi o primeiro documento resultante dessas ações dos órgãos internacionais. Seu objetivo era o de garantir o atendimento às necessidades básicas de aprendizagem de todas as crianças jovens e adultos (UNESCO, 1990).

Outro documento a se destacar consiste na Declaração de Salamanca (1994), considerada marco para as políticas de educação inclusiva, visto que defendeu pela primeira vez a educação de pessoas com deficiência no ensino regular (UNESCO, 1994). Bartalotti (2006) entende que é fundamental a garantia da convivência e da partilha dos recursos e oportunidades oferecidas pela sociedade.

Do ponto de vista legal, os pressupostos inclusivistas de igualdade de oportunidades e de educação para todos ganham notoriedade. Entretanto, Bezerra e Araújo (2010) entendem que há a criação de um mecanismo neoliberal que pretende "humanizar" as ações do capitalismo nesse cenário de crise, barbárie e negação de direitos. Voltando-se aos interesses das pessoas e instituições relacionados ao problema da inclusão escolar, o discurso sobre a educação ocupa um lugar cada vez mais destacado no plano ideológico.

Nesse sentido, “[...] a realidade pôde ser escamoteada, escondida e nós passamos a ter a impressão de lutar por um mundo melhor, pela participação de todos na vida coletiva, sem nenhuma forma de exclusão e preconceitos” (BEZERRA; ARAÚJO, 2010, p. 257).

Esse discurso "transformador", com argumentos convincentes e metas inquestionáveis, ao utilizar os princípios morais como o da aceitação do outro e o das diferenças, os manipulam em 
favor de uma sociedade desigual, injusta, exploradora e excludente, porque não é possível sustentar nenhuma forma de inclusão em um sistema que, ontologicamente ${ }^{2}$, alimenta-se da exclusão (BEZERRA; ARAÚJO, 2010).

Segundo Thoma e Kraemer (2017), a emergência da inclusão esteve voltada aos interesses políticos e econômicos de um modelo neoliberal que buscava a participação de todos os sujeitos da sociedade e no desenvolvimento da nação. No caso do Brasil, o país lutava contra os índices de miséria, a favor de direitos básicos como saúde e educação. Portanto, isso ocorreu dada a obrigatoriedade internacional de o país melhorar o seu desempenho (LOPES; FABRIS, 2016).

Nesse período de instabilidade nacional, o Brasil se abriu para um novo paradigma econômico de acumulação de capital. Destarte, essa ideologia neoliberal é retratada por Carinhato (2008) como uma relação de superioridade econômica, política e moral e de regulação sobre o Estado, com vistas à manutenção de interesses do mercado. Nesse modelo, a ação econômica do Estado criaria privilégio para alguns e dependência para muitos.

No Brasil, o início das políticas neoliberais ocorreu na era Collor (1990-1992) e se intensificou no governo de Fernando Henrique Cardoso (FHC) (1995-2002). Este último estabeleceu o elo de viabilização e sustentação de órgãos internacionais como o FMI, permitindo a execução de reformas no país, preconizadas pelo Banco Mundial. (CARINHATO, 2008).

No governo Lula (2003-2010), houve algumas rupturas em relação ao modelo de seu antecessor, principalmente em relação à tentativa de resgate de direitos e garantias estabelecidos pela CF/1988. Destacam-se a recuperação do papel protagonista do Estado Federal, bem como a tentativa de correção de distorções naturais de um país com extensas dimensões territoriais e com suas diferenças regionais. Não obstante, esse governo assegurou a per-

2 A palavra ontologia é definida por Saviani (2007) como sendo o produto das ações dos homens por meio de suas atividades humanas 
manência em relação às políticas anteriores ao adotar instrumentos de desempenho educativo em consonância com os padrões internacionais de competitividade (OLIVEIRA, 2009).

Logo, as políticas públicas educacionais pós-anos 1990 se alinharam para o que Silva (2014) chamou de princípios da economia da educação de base: equitativa, baseada nos princípios inclusivistas, "camuflando-se" um discurso democrático, porém alicerçados nas teorias educacionais de bases econômicas.

Essas teorias têm como princípio o método de gerenciamento produtivo, promovido pela nova organização do sistema neoliberal, de acumulação flexível, utilizando a escola como um ambiente apenas de preparação laboral dos sujeitos. Segundo Saviani (2005), esta formação educacional tem como um de seus princípios o neotecnicismo, que consiste em uma refuncionalização do tecnicismo característico dos anos de 1970.

Há, dessa forma, uma necessidade para a formação geral de um trabalhador polivalente, que exerça múltiplas funções a partir de uma formação certificatória, ou seja, uma qualificação que está em conformidade com as necessidades de um mercado em constante transformação.

É importante destacar que não existe nenhuma preocupação com a formação humana e social do indivíduo, apenas com a necessidade produtiva. No entendimento de Mira e Romanowisk (2009, p. 10213 - 10214),

[...] a função educacional passa a ser a de habilitar as pessoas a competir no mercado de trabalho, ampliando suas condições de empregabilidade. Configura-se, assim, uma "pedagogia da exclusão", que objetiva preparar os indivíduos, por meio de cursos diversos, de modo que consigam escapar da condição de excluídos. De certo modo, essa pedagogia traz novamente à tona a questão da meritocracia, na medida em que o indivíduo é que assume a culpa pela sua não colocação no mercado de trabalho (afinal, a educação foi democratizada!).

Essa função educacional, excludente e "contraditória" aos documentos inclusivos implementados no país, obrigou, de certa 
maneira, mudanças na condução das políticas educativas, a fim de que grupos minoritários não estivessem à margem desse processo. Neste sentido, Bartalotti (2006) caracteriza a criação de políticas inclusivas compensatórias (reparadoras, assistencialistas e não transformadoras). Com isso, as

Leis gerais inclusivas seriam aquelas que, sem mencionar este ou aquele segmento da população, dão clara garantia do direito, do benefício ou serviço a todas as pessoas, sem distinção de cor, gênero ou deficiência. Este tipo de lei ainda está por ser formulada (SASSAKI, 2006, p. 152).

No entendimento de Silva (2014), essas leis não pretendem equacionar as desigualdades, mas sim criar políticas compensatórias, de uma cultura comum, prevalecendo os aspectos quantitativos sobre os qualitativos.

Dessa forma, o discurso educacional de qualidade total é substituído no século XXI por políticas educacionais fomentadas pela garantia de acesso, permanência e sucesso a todas as pessoas. Para Lopes e Fabris (2016), foi inventada uma atmosfera hodierna para democratizar acessos, para garantir "igualdade a todos", por um movimento de direita. Essas políticas públicas pautam-se em indicadores avaliativos de natureza externa (SAEB / Prova Brasil, ENEM, Provinha Brasil, entre outras), e têm a finalidade de verificar em que medida o sistema está produzindo os resultados que dele se espera, sob a lógica da competitividade, da concorrência e da hierarquia (MIRA; ROMANOWISK, 2009).

No ensino superior, houve uma expansão massiva a partir do governo de FHC nos anos de 1990, com a criação de vários cursos em instituições privadas, principalmente dos chamados tecnólogos, de formação rápida para o mercado. Nesse formato de educação, instituíram-se as políticas de avaliação da Educação Superior, como o Exame Nacional de Cursos (ENC), como uma maneira de "aferir a qualidade" do ensino em conformidade com os pressupostos mercadológicos.

O Sistema Nacional de Avaliação da Educação Superior (SINAES), já no governo LULA, a priori, tinha como meta a avaliação 
das instituições em relação ao ensino, pesquisa e extensão, garantindo o acompanhamento formativo do processo na perspectiva de autoconhecimento das instituições. Entretanto, logo sucumbiu ao sistema de regulação gerencialista, criando em 2008 dois novos índices (CPC - Conceito Preliminar de Curso e IGC - Índice Geral de Cursos da Instituição da Educação Superior) $)^{3}$.

Para Ribeiro (2012), esses mecanismos avaliativos estão direcionados à melhoria da qualidade da educação com a finalidade de promover maior competitividade, pressupostos de uma educação classificatória, imediatista e finalística, seguindo os critérios economicistas e gerenciais das empresas.

Pensando na escolarização das pessoas com deficiência Silva (2014) ressalta uma transição, aproximadamente nos últimos 15 anos, da perspectiva de inclusão desse público na escola regular com o apoio complementar do Atendimento Educacional Especializado (AEE), dadas as necessidades específicas de aprendizagem. Esse processo foi realizado de modo precário, uma vez que grande parte desse alunado, inserido nas salas de aula da escola regular, está sem receber nenhum tipo de suporte de escolarização. A LDBEN/1996 prescreve aos sistemas de ensino que sejam garantidos a esses estudantes, conforme o artigo 59, "I - currículos, métodos, técnicas, recursos educativos e organização específicos, para atender às suas necessidades; [...]" (BRASIL, 1996, p. 19).

Em outros níveis de ensino, como na educação profissional e tecnológica, percebe-se uma preocupação de políticas voltadas a esse público apenas para a formação de mão de obra para o mercado de trabalho. O PRONATEC (Programa de Ensino Técnico e Emprego $)^{4}$, criado no governo Dilma Rousseff (2011-2016), esta-

Fase governamental do mandato do presidente Lula que apresentou a criação de dois novos indicativos aplicados no contexto da educação brasileira descumprindo e contrariando a expectativa do SINAES de uma avaliação participativa e formativa e não reguladora (RIBEIRO, 2012).

4 Lei no $12.513 / 2011$ - tem como um de seus objetivos estimular a articulação entre a política de educação profissional e tecnológica e as políticas de geração de trabalho, emprego e renda (BRASIL, 2011). 
belece em seu Art. $2^{\circ}, \int 2^{\circ}$, sobre a participação das pessoas com deficiência nas ações de educação profissional e tecnológica desenvolvidas no âmbito do Programa, as condições de acessibilidade como adequação de equipamentos, de materiais pedagógicos, de currículos e de estrutura física. (BRASIL, 2011).

Em 2012, o governo disponibilizou 20 mil vagas para esse público em cursos de formação inicial e continuada por meio da Bolsa - Formação Trabalhador (BRASIL, 2012a). Todavia, não houve um acompanhamento e divulgação do número de beneficiados que efetivamente ingressou no mundo do trabalho, ou se realmente permaneceram em uma "falsa inclusão educacional".

Essa preocupação com a oferta e a ampliação do número de vagas na educação que contemple a todos é justificada em função do crescente número de pessoas com algum tipo de deficiência em idade economicamente ativa no Brasil. A Cartilha do Censo das pessoas com deficiência, em 2010, apontou que 23,9\% da população apresentavam algum tipo de limitação física e ou sensorial. Entre os anos 2000 e 2010 houve um aumento de 4\% na faixa etária de 15 a 64 anos. O número de pessoas com deficiência entre 0 a 14 anos elevou-se para 3,2\% (BRASIL, 2012b).

De acordo com Thoma e Kraemer (2017), os dados do censo escolar dos alunos com deficiência mostraram que o ingresso entre os anos de 1998 a 2006 cresceu 640\%, subindo de 43.923 estudantes em 1998, para 325.316 em 2006. O Anuário Brasileiro da Educação Básica (2018) desvelou o número de matrículas de alunos com deficiência entre os anos de 2008 a 2016. Os dados evidenciaram um crescimento de $82 \%$ desse público nas classes regulares (TODOS PELA EDUCAÇÃO, 2018).

Deste modo, o funcionamento das políticas contemporâneas visa incluir todos por intermédio de uma economia neoliberal, concretizada por uma intensa política social, a qual realiza constantemente registros sobre essa população, quantificando os aspectos mais característicos e de interesse, formulando saberes para posteriormente disponibilizá-los aos governos e à sociedade (THOMA; KRAEMER, 2017). 
Nesse contexto, em que o conhecimento é objeto de exploração do capital, há uma apropriação desses sujeitos enquanto um grupo em "potencial" para a produtividade no mercado e para o consumo. Para isso, utiliza a escola como elemento importante para esse processo de formação e de preparação.

Assim, o neotecnicismo destaca o papel do gerente (diretor), do gestor (professor) e do cliente (aluno), colocando também em evidência o "fornecedor" e o "executor" em uma vertente acentuadamente tecnocrática. É importante compreender que os conceitos estabelecidos nessa teoria como "qualidade", "técnica" e "eficiência" presentes nas políticas educacionais brasileiras, não priorizam a igualdade do acesso, da permanência e do sucesso em educação.

Há um direcionamento de investimentos do Estado em uma educação voltada aos processos de subjetivação dos indivíduos, isto é, fazer da inclusão uma das condições de sua própria existência. Logo, esse modelo dissemina a ideia de que todos serão responsáveis por si e por todos, mascarando a inclusão, em prol de uma subjetividade, visto que essa estratégia de Estado utiliza essa "roupagem" para manter a individualização dos sujeitos (LOPES; FABRIS, 2016). "Isso significa desenvolver uma forma de ser que conduz os indivíduos a se ocupar com o outro, capitalizando para si mesmos condições de competição" (LOPES; FABRIS, 2016, p. 67).

Uma das críticas a esse modelo é a constante mudança nas escolas em função dos ajustes que o sistema laboral impõe, ou seja, a escola como um modelo voltado às necessidades do mercado. Desse modo, reforça as desigualdades e diferenças de classe, gênero e raça (SACRISTÁN, 2013).

Entende-se a ideologia progressista como uma forma de superação desse atual modelo de educação visto que "[...] tem enfatizado o que é bom para se obter maior equidade [...] em uma escola única, não diferenciada, com uma estrutura cada vez mais extensa de ensino comum [...]" (SACRISTÁN, 2013, p. 29).

Neste sentido, a pedagogia libertadora surge como alternativa de compreensão crítica da realidade e de sua transformação 
social, segundo a qual a educação tem um papel ímpar, o de proporcionar uma formação em sua totalidade, direcionada às reais necessidades humanas.

\section{Contribuições da pedagogia libertadora para a educação inclusiva}

A pedagogia libertadora surge, no final dos anos de 1950 e início dos anos de 1960, como um processo de mobilização popular em prol da cultura e da educação pautada nos movimentos sociais. Tem como pressupostos as ideias de Paulo Freire e está em consonância com a educação concebida como ferramenta de libertação dos oprimidos, referindo-se aos excluídos de sua época, sobretudo os adultos pobres e analfabetos. Assim, defendia uma educação voltada à construção da consciência e do pensamento crítico por meio do diálogo, considerando seu contexto de vida como elementos imprescindíveis contra a alienação e a exploração instauradas pela classe dominante.

É importante ressaltar que nesse período não havia discussões em torno de uma educação inclusiva, porém, já existia a preocupação de Paulo Freire com os oprimidos. Neste sentido:

Em tempos de exclusão, podemos dizer que Paulo Freire ainda é muito atual, assim como suas concepções de mundo e de educação. Sua práxis como educador traz elementos importantes para se pensar em um projeto de educação, instrumento de transformação e libertação (OLIVEIRA; LEITE, 2012, p. 45).

Para a discussão utilizou-se como referencial as seguintes obras de Paulo Freire: "Conscientização: teoria e prática da libertação: uma introdução ao pensamento de Paulo Freire"; "Pedagogia da autonomia: saberes necessários à prática educativa" e "Educação como Prática de Liberdade".

Na obra "Conscientização: teoria e prática da libertação: uma introdução ao pensamento de Paulo Freire”, há uma preocupação com o processo de formação crítica das pessoas que deve conduzi-las a um posicionamento utópico (realizável) frente ao mundo, ao 
"[...] denunciar a estrutura desumanizante e de anunciar a estrutura humanizante" (FREIRE, 1979, p. 16).

Isso decorre da necessidade de um posicionamento crítico em que é fundamental conhecer as estruturas desumanizantes de poder que se traduzem em ações opressoras que cerceiam e moldam as pessoas em vários segmentos da sociedade, para a posteriori, denunciá-las. Quanto maior a capacidade de reflexão e de criticidade, maior será o poder de transformação das pessoas e a possibilidade de transição para uma estrutura humanizante. Dessa forma, a conscientização produz um rompimento criado pelos opressores como forma de dominação e de manutenção do status quo (FREIRE, 1979).

Podemos realizar um comparativo com as estruturas educacionais gerencialistas, excludentes que entendem o indivíduo como um executor de tarefas produtivas, desconsideram a formação humana, de acordo com os interesses do sistema neoliberal. Assim, à época, Freire (1979) já propunha mudanças na formação dos educandos em relação a esses sistemas considerados alienantes e que imergiam os sujeitos em uma relação de desigualdades. É fundamental que esta conscientização seja o objetivo mais importante da educação: o de "[...] provocar uma atitude crítica, de reflexão, que comprometa a ação" (FREIRE, 1979, p. 22).

Esta ação crítica valoriza o contexto de vida das pessoas de que se pretende educar e isso coaduna com os princípios de uma educação inclusiva, para todos, em que a diversidade humana; o multiculturalismo e as diferenças se constituem em elementos fundantes nesse processo reflexivo e de aprendizagem.

Paulo Freire defende uma nova relação pedagógica que abandona uma educação estática e compartimentada, em que os conhecimentos são depositados, e, por consequência, desconsideram as experiências de vida, as potencialidades e características dos estudantes.

Dessa maneira, é essencial uma educação problematizadora, crítica, que sobreleva os sujeitos como seres inacabados, históricos, e que valoriza sua relação com o mundo em um processo dialógico de reflexão-ação (unidade dialética), balizando-se em uma peda- 
gogia utópica que traz como essência a conscientização capaz de romper com as estruturas injustas de uma sociedade conservadora (FREIRE, 1979).

Em sua obra, "Pedagogia da autonomia: saberes necessários à prática educativa”, Paulo Freire defende o ensino contra qualquer forma de discriminação, a prática preconceituosa de raça, de classe e de gênero e que "[...] ofende a substantividade do ser humano e nega radicalmente a democracia" (FREIRE, 2007, p. 36).

No capítulo três, "Ensinar é uma especificidade humana", Freire estabelece uma discussão sobre a autonomia docente no ensino, que não se restringe ao ato de transferir conhecimento. É imprescindível que o processo reflexivo se inicie por aquele que ensina, para, posteriormente, despertar o senso crítico dos estudantes. Salienta a necessidade de o docente reconhecer o campo ideológico educacional, suas mazelas e os discursos que camuflam a realidade (FREIRE, 2007).

Isso é fundamental, principalmente em um contexto político educacional caracterizado por um discurso inclusivista que estabelece a garantia de igualdade de direitos em relação ao acesso, à permanência e ao sucesso escolar. Todavia, a prática se revela contraditória, visto que há um modelo educacional que adestra os sujeitos em prol de uma sociedade produtivista. Aqueles que não se enquadram nesse padrão educacional neoliberal, permanecerão excluídos desse ambiente de aprendizagem.

Destaca-se, nesse processo, o surgimento de incompreensão e de ingenuidade reflexiva docente em relação ao campo ideológico que contribuem com a disseminação e o fortalecimento de um modelo vigente de alienação e exclusão. Todavia, Freire explica que muitas vezes esses sujeitos têm consciência de que são dominados, porém “[...] estão imersos na realidade opressiva e impede-lhes uma percepção clara de si [...]” (FREIRE, 1979, p.31). Desse modo, caberá uma conscientização desses sujeitos no sentido de "[...] desvelar a realidade, desmarcarar a sua mitificação [...]” (FREIRE, 1979, p. 17). 
Outro aspecto de destaque é a disponibilidade, a abertura docente ao diálogo, responsável por despertar a inquietação e a curiosidade dos estudantes, eixo fundamental para os princípios de uma educação inclusiva. A partir do diálogo, há a promoção do estreitamento das relações entre docentes e estudantes, em uma via de mão dupla, viabilizando novas possibilidades de se compreender o outro, de conhecer potencialidades, de respeito à capacidade e condições de aprendizagem de cada um.

Esse processo se constrói a partir do chão da escola, do trabalho reflexivo e problematizador do docente junto de seu grupo de estudantes e isso se caracteriza como uma forma de superação de um modelo opressor de ensino. Essa abertura de ideias e de liberdade de pensamentos permitem o entendimento de uma escola plural e democrática que concebe o direito de todos ao aprendizado e de respeito às individualidades.

Nesse sentido, há uma busca por uma educação comprometida com os problemas da comunidade, do local; "da vida do povo", por intermédio de uma prática mediada pelo diálogo e pela valorização da cultura dos sujeitos. Compreende-se que a educação é um instrumento de transformação para que uma sociedade se torne justa e igualitária. Assim, somente o diálogo poderá interagir e promover uma práxis libertadora que inclua; que não se conforma com a reprodução. Efetiva-se mediante da construção coletiva, crítica, política, consciente e reflexiva com base em uma educação enquanto ambiente de transformação. (OLIVEIRA; LEITE, 2012).

Em seu livro, "Educação como Prática de Liberdade", no capítulo três, intitulado Educação versus Massificação, Freire (2009) alerta para a necessidade de uma sociedade que garanta ao homem uma formação democratizadora e consciente. Esses sujeitos devem exercer um papel questionador e investigador frente ao processo de dominação dos direitos políticos instituído pelo poder desumano exercido pelas classes muito ricas sobre os oprimidos.

Por este motivo, é imprescindível uma educação que caminhe na construção de uma consciência crítica, por meio do incen- 
tivo à "[...] pesquisa e da constatação, da revisão dos achados [...]" (FREIRE, 2009, p. 102). Paulo Freire defende um sistema educacional prioritário à humanização do povo brasileiro, principalmente pela transição à tecnologia pela qual a sociedade atual se encontra, não permitindo que a formação dos homens seja apenas técnica, de caráter acrítico e ingênuo (FREIRE, 2009).

A humanização das pessoas perpassa por uma educação para a liberdade que comunga com os ideais de uma educação inclusiva. Concebe uma formação pautada na realidade dos estudantes do ponto de vista histórico, político e social por meio de situações-problema. Dessa maneira, oportuniza a compreensão das diferenças e de respeito de mútuo entre as pessoas, importantes nesse processo de emancipação.

Essa formação perpassa por meio de um currículo escolar que leva em conta as influências históricas da sociedade, a fim de que se estabeleça uma discussão dialógica com vistas à elaboração de um currículo reflexivo, de valorização de outros saberes e de recriação do conhecimento (SACRISTÁN, 2013).

Portanto, se opõe a um modelo historicamente pensado e estruturado na seleção de saberes, elaborado sob influência de concepções ideológicas dominantes, na padronização do ensino escolar e do processo de aprendizagem por meio da transmissão de conteúdos.

As concepções de educação de Paulo Freire permitem uma reflexão de que é possível, por meio de uma educação dialógica; problematizadora, criar mecanismos de superação frente a um sistema educacional neotecnicista, excludente. Fornecem elementos capazes de se pensar em uma educação inclusiva com uma identidade própria, para além de um discurso camuflado de educação para todos, mas de um ambiente de respeito, de valorização social e de construção crítica e coletiva.

\section{Considerações finais}

As políticas educacionais inclusivas, dos séculos XX e XXI, são elaboradas a partir de um discurso inquestionável, convincente, 
de caráter humanizador, voltadas à garantia de igualdade de direitos e de educação de qualidade para todos em uma sociedade neoliberal. O que existe de fato é um sistema econômico que cria mecanismos para transmitir a ilusão de uma sociedade inclusiva, visto que se apresenta sob a influência de uma base econômica educacional em que a escola assume um papel gerencial na formação dos sujeitos conforme as demandas de mercado.

Assim, prevalece uma formação individualista, competitiva, restrita à produtividade, desconsiderando princípios basilares como a formação humana, cidadã, crítica e participativa. Portanto, é criado um movimento político educacional a favor de uma pseudo-inclusão, que nada mais é do que uma apropriação do sistema neoliberal àquelas pessoas que sempre estiveram à margem da sociedade. Com isso, a partir de um novo modelo de acumulação em que os meios de exploração passam pela formação educacional do indivíduo, logo, os até então excluídos, passam a ser importantes neste contexto de produção e de consumo.

Deste modo, entende-se a necessidade de uma educação que modifique esse contexto com propostas de um ensino crítico e transformador que efetivamente se preocupe com a formação emancipatória, capaz de confrontar e modificar os problemas decorrentes do neotecnicismo pedagógico.

Ainda que a pedagogia libertadora de Paulo Freire tenha surgido na metade do século XX, defende pressupostos relevantes em um projeto de educação libertadora e transformadora em decorrência do atual contexto educacional de inclusão-exclusão. Por conseguinte, estabelece elementos fundantes da educação dialógica como transformadora da consciência crítica, a partir da valorização do contexto social dos educandos contra uma falsa homogeneização estabelecida pelo capitalismo neoliberal. Só assim será possível promover efetivamente uma educação para todos, sem discriminações de qualquer natureza. 


\section{Referências}

BARTALOT'TI, C. C. Inclusão das pessoas com deficiência: utopia ou possibilidade? São Paulo: Paulus, 2006.

BAUMAN, Z. Modernidade Líquida. Rio de Janeiro: Jorge Zahar, 2001.

BEZERRA, G. F; ARAÚJO, D. A. C. As aparências enganam: a pretexto de uma crítica sobre o ideário inclusivista. Educere Et Educare. Cascavel, v. 05, n. 9, p. 253-266, jan./jul., 2010. Disponível em:

$<$ htp://e-revista.unioeste.br/index.php/educereeteducare/article/view/2690>. Acesso em: 01 fev. 2020.

BRASIL. Constituição (1988). Constituição da República Federativa do Brasil. Brasília, DF. Senado, 2020. Disponível em: <https://www2.senado.leg.br/bdsf/ bitstream/handle/id/566968/CF88_EC105_livro.pdf>. Acesso em: 04 set. 2020.

BRASIL. Lei de Diretrizes e Bases da Educação Nacional. Lei n ${ }^{\circ}$ 9.394, 20 de dezembro de 1996. Estabelece as diretrizes e bases da educação nacional. 13. Ed. Brasília, DF, 1996. Disponível em: < http://portal.mec.gov.br/index.php?option=com_content\&view $=$ article\&id=12907:legislacoes\&catid=70es:legislaco $>$. Acesso em: 14 abr. 2018.

BRASIL. Lei $\mathbf{n}^{\circ}$ 12.513, de 26 de outubro de 2011. Institui o Programa Nacional de Acesso ao Ensino Técnico e Emprego. Brasília, DF, 2011. Disponível em: <http://www.planalto.gov.br/ccivil_03/_ato2011-2014/2011/lei/112513.htm>. Acesso em: 19 maio 2019.

BRASIL. Ministério da Educação, Pronatec reserva 20 mil vagas para pessoas com deficiência, 2012a. Disponível em: < http://portal.mec.gov.br/ultimas-noticias/205-1349433645/18019-pronatec-reserva-20-mil-vagas-para-pessoas-com-deficiencia>. Acesso em: 22 jun. 2019.

BRASIL. Secretaria de Direitos Humanos da Presidência da República, Secretaria Nacional de Promoção dos Direitos da Pessoa com Deficiência. Cartilha do Censo 2010: pessoas com deficiência. Brasília, DF; 2012b. Disponível em: <https:// www.pessoacomdeficiencia.gov.br/app/sites/default/files/publicacoes/cartilha-censo-2010-pessoas-com-deficienciareduzido.pdf> . Acesso em: 19 maio 2019.

CARINHATO, P. H. Neoliberalismo, reforma do estado e políticas sociais nas últimas décadas do século XX no Brasil. Aurora. Marília, v. 02, n. 1, p. 37-46, dez. 2008. Disponível em: <http://www2.marilia.unesp.br/revistas/index.php/auro$\mathrm{ra} /$ article/view/1192>. Acesso em: 13 maio 2019. 
DI GIORGI, C. A. G. Concepções do Banco Mundial e outros organismos internacionais sobre educação: problemas e contradições. Revista Nuances - v. II - out. 1996. Unicamp, SP.

FREIRE, P. Conscientização: teoria e prática da libertação: uma introdução ao pensamento de Paulo Freire. Trad. de Kátia de Mello e Silva. São Paulo: Cortez \& Moraes, 1979.

FREIRE, P. Pedagogia da autonomia: saberes necessários à prática educativa. 35. ed. São Paulo: Paz e Terra, 2007.

FREIRE, P. Educação como prática de liberdade. 32. ed. Rio de Janeiro: Paz e Terra, 2009.

LOPES, M. C; FABRIS, E. H. Inclusão \& educação. 1. ed. Belo Horizonte: Autêntica Editora, 2016.

MANTOAN, M. T. E. Inclusão escolar: O que é? Por quê? Como fazer? São Paulo: Moderna, 2003.

MIRA, M. M; ROMANOWISK, J. P. Tecnicismo, neotecnicismo e as práticas pedagógicas no cotidiano escolar. In: CONGRESSO NACIONAL DE EDUCAÇÃO - EDUCERE, 9, 2009, Curitiba. Anais eletrônicos [...] Curitiba, 2009. Disponível em: <http://www.marcelo.sabbatini.com/wp-content/uploads/ downloads/neotecnicismo.pdf>. Acesso em: 22 jun. 2019.

OLIVEIRA, D. A. As políticas educacionais no governo lula: rupturas e permanências. RBPAE. Porto Alegre, v. 25, n. 2, p. 197-209, mai./ago. 2009. Disponível em: <https://seer.ufrgs.br/rbpae/article/view/19491>. Acesso em: 13 maio 2019.

OLIVEIRA, F. S; LEITE, L. H. A. A atualidade do pensamento de Paulo Freire e sua contribuição para a educação no Brasil. Paideia, Belo Horizonte, n. 13, p. 43-56, jul./dez., 2012. Disponível em: < http://www.fumec.br/revistas/paideia/ article/view/1670>. Acesso em: 22 jun. 2019.

RIBEIRO, E. A. As atuais políticas públicas de avaliação para a educação superior e os impactos na configuração do trabalho docente. Avaliação. Campinas, v. 17, n. 2, p. 299-316, jul, 2012. Disponível em: < www.scielo.br/scielo.php?script $=$ sci_arttext\&pid $=$ S1414-40772012000200002\&lng=pt\&tlng=pt $>$. Acesso em: 22 maio 2019.

SACRISTÁN, J. G. O que significa currículo? In: SACRISTÁN, J. G. (Org.). Saberes e incertezas sobre o currículo. Porto Alegre: Penso, 2013. p. 16-35. 
SASSAKI, R. K. Inclusão: construindo uma sociedade para todos. 7. ed. Rio de Janeiro: WVA, 2006.

SAVIANI, D. As concepções pedagógicas na história da educação brasileira. Revista HISTEDBR On-line, Campinas, p.1-38, 2005. Disponível em: <http:// www.histedbr.fe.unicamp.br/navegando/artigos_frames/artigo_036.html >. Acesso em: 5 abr. 2019.

SAVIANI, D. Pedagogia histórico-crítica: primeiras aproximações. 10. ed. rev. Campinas, SP: Autores Associados, 2008.

SAVIANI, D. Trabalho e educação: fundamentos ontológicos e históricos. 2007.

SILVA, L. C; MARQUES, M. R. A. A inclusão social e educacional nos 25 anos da aprovação da Constituição Federal de 1988. RBPAE. v. 29, n. 2, p. 347-365, 2013. Disponível em: <https://seer.ufrgs.br/rbpae/article/view/43528>. Acesso em: 22 out. 2019.

SILVA, R. H. Contribuições da pedagogia histórico-crítica para a educação especial brasileira. Revista HISTEDBR On-line, Campinas, n. 58, p. 78-89, 2014. Disponível em: <https://periodicos.sbu.unicamp.br/ojs/index.php/histedbr/article/view/8640380>. Acesso em: 2 jun. 2019.

THOMA, A. da S.; KRAEMER, G. M. A educação de pessoas com deficiência no Brasil: políticas e práticas de governamento. 1. ed. Curitiba: Appris editora, 2017.

TODOS PELA EDUCAÇÃO. Anuário Brasileiro da Educação Brasileira 2018. São Paulo: Moderna, 2018. Disponível em: < https://todospelaeducacao. org.br/conteudo/anuario-brasileiro-da-educacao-basica-2018-disponivel-download >. Acesso em: 28 jun. 2020.

UNESCO. Declaração Mundial sobre Educação para Todos: Satisfação das Necessidades Básicas de Aprendizagem, Jomtien, 1990. Disponível em: < https:// unesdoc.unesco.org/ark:/48223/pf0000086291_por>. Acesso em: 18 jun.2019.

UNESCO. Declaração de Salamanca. Sobre Princípios, Políticas e Práticas na Área das Necessidades Educativas Especiais, Salamanca, 1994. Disponível em: http://portal.mec.gov.br/seesp/arquivos/pdf/salamanca.pdf. Acesso em: 10 maio 2019. 